\title{
Outbreak of Zika in Singapore sparks warnings in neighbouring countries
}

\author{
Owen Dyer
}

Montreal

Zika virus disease has a foothold in Singapore-a major travel hub-and the outbreak is spreading beyond its initial epicentre, a large building site hosting many foreign workers.

Twenty eight new cases were confirmed on 30 August; at least five of them were contracted outside the district where the men worked. The total number of confirmed cases since the outbreak was announced at the weekend stands at $82 .{ }^{1}$

Most of the cases were found through general practitioners: the health ministry was first alerted to Zika's arrival by a phone call from three GPs at a local clinic who had identified a cluster of mild fever with joint pain. The first case subsequently confirmed was that of a 47 year old Malaysian woman on 31 July. She lived on a major road adjacent to the building site.

Most of the patients whose cases are now confirmed have already made a full recovery from mild symptoms. The government urged pregnant women from any district to take a free Zika test if they experienced any symptoms.

Australia, Taiwan, Britain, and South Korea have issued travel warnings to pregnant women.

Malaysia has begun health checks on bus passengers entering Johor Bahru, a border city through which almost 200000 Malaysian commuters pass daily on their way to jobs in Singapore.

Indonesia has set up body temperature cameras in its airports and nearby ports, but the effectiveness of these devices is unclear as many Zika patients are asymptomatic and the incubation period is up to 12 days.

About 55 million passengers pass through Singapore's Changi Airport each year and the city-state receives about eight million tourists a year.
Singapore and neighbouring countries are already familiar with dengue fever and mosquito control measures are widespread. They were already in place at the building site where Zika first took hold, infecting at least 36 people. All 490 workers on the site have been ordered to stop work and are sleeping in temporary accommodation in what the health ministry described as "voluntary quarantine." They have been instructed to apply mosquito repellent every hour, and to chew vitamin $\mathrm{C}$ tablets, anecdotally believed in Singapore to protect against dengue.

Officials at the National Environmental Agency continued to spray and fumigate the cluster area. They also inspected about 5000 of 6000 premises, serving notices at inaccessible sites where they would force entry. They detected and destroyed 39 mosquito breeding habitats, 23 of them in homes.

Mosquito control measures were also being stepped up in Florida in the US, where a more slowly moving outbreak persists. The US Food and Drug Administration has ordered the testing of stored blood samples after Zika was found in blood donated from Florida.

Researchers at the University of Texas Medical Branch said this week that they had seen Zika virus pass from infected mosquitoes to their eggs, larvae, and offspring. ${ }^{1}$ One in 290 mosquitoes reared from the eggs of female mosquitoes injected with the virus under laboratory conditions also carried Zika. Such vertical transmission has yet to be observed in the wild but could confound eradication efforts, as spraying typically does not kill eggs or larvae.

Thangamani S, Huang J, Hart CE, Guzman H, Tesh RB. Vertical transmission of Zika virus in mosquitoes. Am J Trop Med Hyg 2016;16-0448. doi:10.4269/ajtmh. 16-0448.Yjm. pmid:27573623.

Published by the BMJ Publishing Group Limited. For permission to use (where not already granted under a licence) please go to http://group.bmj.com/group/rights-licensing/ permissions 